\title{
Fluoroalcohols: Efficient Solvents for the lodine(III)-Promoted Oxidative Rearrangement of 1,2-Dihydronaphthalenes
}

\author{
Eloisa E. Ishikawa ${ }^{\dagger}$, André Fogaça ${ }^{\dagger}$, Andréa T. Faccio ${ }^{\dagger}$, Vânia M. T. Carneiro ${ }^{\dagger}$, Aline \\ Utaka $^{\dagger}$, Iris R. M. Tébéka ${ }^{\dagger}$, Marcin Bielawski ${ }^{\dagger \ddagger}$, Berit Olofsson ${ }^{\ddagger}$, Luiz F. Silva, Jr. ${ }^{\dagger *}$ \\ †'Instituto de Química, USP, CP 26077, CEP 05513-970 São Paulo SP, Brazil, ${ }^{\ddagger}$ Department of Organic \\ Chemistry, Arrhenius Laboratory, Stockholm University, SE-106 91 Stockholm, Sweden \\ *luizfsjr@iq.usp.br
}

Keywords: Fluoroalcohols, Hypervalent lodine, Oxidative Rearrangement.

\section{INTRODUCTION}

Hypervalent iodine reagents have a key role in chemical synthesis. ${ }^{1}$ Since the first report, ${ }^{2} \mathrm{CF}_{3} \mathrm{CH}_{2} \mathrm{OH}$ (TFE) and $\left(\mathrm{CF}_{3}\right)_{2} \mathrm{CHOH}(\mathrm{HFIP})$ have been used as solvent in reactions with hypervalent iodine compounds. However, TFE and HFIP have not been used in the rearrangement of alkenes. ${ }^{1}$ We reported the ring contraction of 1,2-dihydronaphthalenes in $\mathrm{MeOH}$ or in MeCN mediated by Phl(OH)OTs (HTIB). ${ }^{3}$ Herein we describe fluoroalcohols as a great alternative for the oxidative rearrangement of alkenes mediated by HTIB. Some of the results in this work were already presented, ${ }^{4}$ and they are shown here for comparison.

\section{RESULTS AND DISCUSSION}

The reactions of the 1,2-dihydronaphthalenes $\mathbf{1 a}, \mathbf{1} \mathbf{b}$ and 1c with HTIB in TFE led to the desired products in higher yields than in $\mathrm{MeOH}^{3}$ (entries 1 and 2, table 1). The oxidation of trisubstituted alkenes $\mathbf{1 d}$ to $\mathbf{1 g}$ with HTIB in TFE gave the corresponding indanes also in very good yields (entries 3, 4 and 5). Although TFE gives higher yields, the diastereoselectivity is lower. ${ }^{3}$ Thus, several conditions were tested to optimize the diastereoselectivity. Eventually, this goal was achieved using a 4:1 mixture of DCM:TFE as the solvent (entries 1 and 2). This media is also appropriate for trisubstituted alkenes (entry 4). Considering the very good results with TFE, we tested the even more polar solvent, HFIP. The oxidation of 1a in HFIP was very fast and led to 3 , but in lower yield than in TFE (entries 1 and 6). To avoid decomposition, 3 was reduced in situ, giving 4 after addition of $\mathrm{NaBH}_{4}$, but in only $34 \%$ yield (entry 6). The alcohol 4 was isolated in better yield using DCM:HFIP (4:1), however together with 5 (entry 7). The treatment of $1 a$ with $\mathrm{HTIB}$ and $\mathrm{H}_{2} \mathrm{O}$ in DCM:HFIP (4:1), followed by $\mathrm{NaBH}_{4}$, led only to 4 in $74 \%$ yield (entry 8 ).

\section{CONCLUSION}

Fluoroalcohols appeared to be an excellent medium for the iodine(III)-mediated ring contraction of 1,2-dihydronaphthalenes. This protocol represents a green alternative to the analogous reaction using toxic thallium(III) salts and will be useful in medicinal and synthetic organic chemistry to access functionalized indanes in an expeditious manner.

TABLE 1. Reaction of alkenes with HTIB in Fluoroalcohols ${ }^{\mathrm{a}}$.

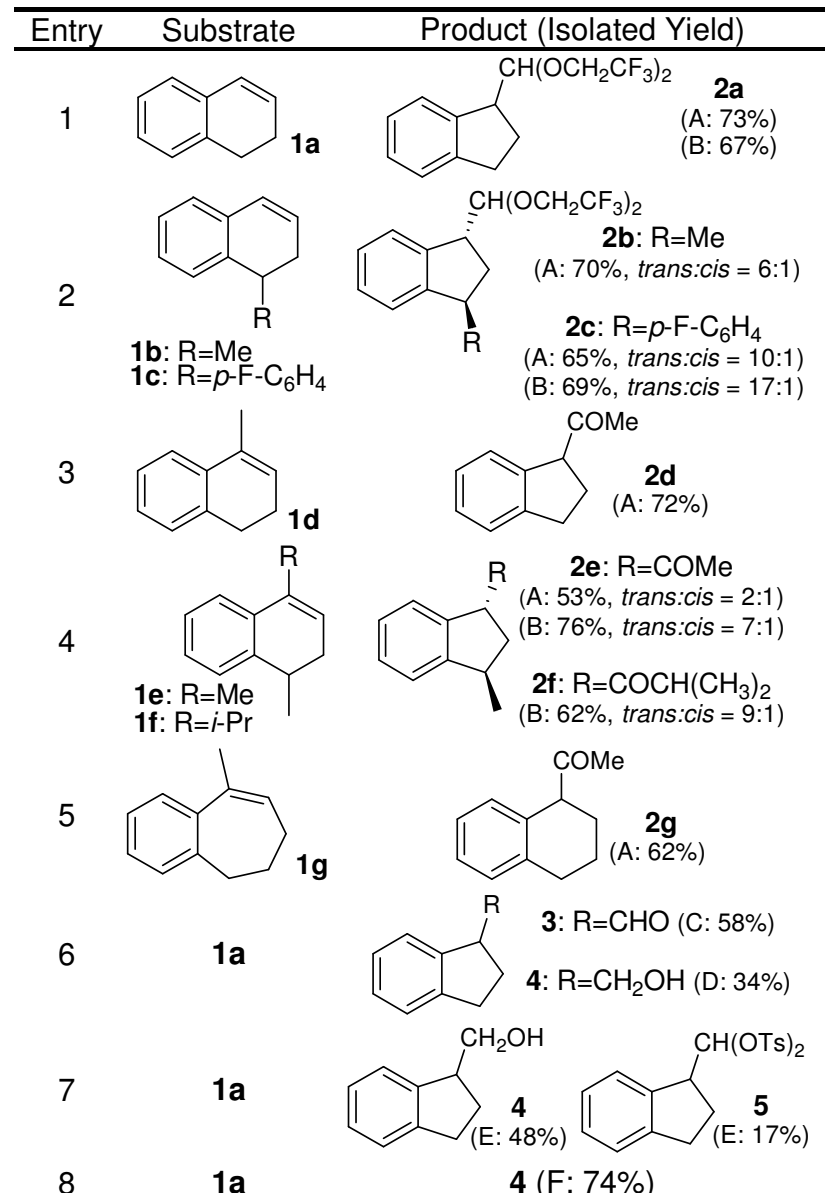

A: TFE; B: DCM:TFE (4:1); C: HFIP; D: i) HFIP, ii) $\mathrm{NaBH}_{4}$. E: i) DCM: $\operatorname{HFIP}$ (4:1), ii) $\mathrm{NaBH}_{4} ; \mathrm{F}$ : i) DCM:HFIP (4:1), 22 equiv $\mathrm{H}_{2} \mathrm{O}$, ii) $\mathrm{NaBH}_{4}$.

\section{ACKNOWLEDGEMENTS}

FAPESP, CNPq and CAPES for financial support.

\section{REFERENCES}

${ }^{1}$ Zhdankin, V. V.; Stang, P. J. Chem. Rev. 2008, 108, 5299. ${ }^{2}$ Yakura, T.; Tohma, H.; Kikuchi, K.; Tamura, Y. Tetrahedron Lett. 1989, 30, 1119. ${ }^{3}$ Silva, L. F., Jr.; Siqueira, F. A.; Pedrozo, E. C.; Vieira, F. Y. M.; Doriguetto, A. C. Org. Lett. 2007, 9, 1433; ${ }^{4 a}$ Silva Jr., L. F.; Ishikawa, E. E.; Almeida Neto, A. F.; Carneiro, V. M. T.; 32thRASBQ 2009, QO-126. ${ }^{4 b}$ Faccio, A. T.; Carneiro, V. M. T.; Silva Jr., L. F.; 33thRASBQ 2010, ORG-019.

$14^{\text {th }}$ Brazilian Meeting on Organic Synthesis $-14^{\text {th }}$ BMOS - September 01-05, 2011-Brasilia, Brazil 